\title{
Using the forest (plots) to see the trees
}

\author{
Bryan A. Whitson, MD, PhD
}

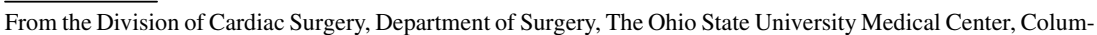
bus, Ohio.

Disclosures: Author has nothing to disclose with regard to commercial support.

Received for publication July 9, 2016; accepted for publication July 11, 2016.

Address for reprints: Bryan A. Whitson, MD, PhD, Director, End-Stage Cardiopulmonary Failure Program,

Co-Director, COPPER Laboratory, Division of Cardiac Surgery, Department of Surgery, The Ohio State University Medical Center, N-816 Doan Hall, 410 W 10th Ave, Columbus, OH 43210 (E-mail: bryan.whitson@ osumc.edu)

J Thorac Cardiovasc Surg 2016;152:1154-5

$0022-5223 / \$ 36.00$

Copyright (c) 2016 Published by Elsevier Inc. on behalf of The American Association for Thoracic Surgery http://dx.doi.org/10.1016/j.jtcvs.2016.07.033
}

Many subtle things that may be difficult to measure or ascertain can have profound effects on our life. Diastolic dysfunction and its effect on outcomes after cardiac surgery, in terms of morbidity and mortality, is one such thing. Diastolic dysfunction, which has the hallmarks of unimpaired rate of left relaxation, reduced compliance, loss of restoring forces, and increased filling pressures, ${ }^{1,2}$ can be very difficult to diagnose. Signs of diastolic dysfunction may be assessed through many imaging modalities although it is typically assessed with echocardiography. In this assessment, the most accepted measurements are an elevated ratio of mitral peak velocity of early filling to early diastolic mitral annular velocity, elevated ratio of peak early to late diastolic filling velocity, or decreased deceleration time. Direct measurements of left ventricular end-diastolic pressure and pulmonary capillary wedge pressure are also able to help guide the picture of diastolic dysfunction assessment. Although direct measurement and cardiac magnetic resonance imaging have a role, echocardiography has been the mainstay of evaluation. ${ }^{1}$ The issue is compounded by the fact that the effect on our outcomes may not always be apparent in the literature because of either the nuanced diagnosis, small sample sizes, or underappreciation.

In this issue of The Journal of Thoracic and Cardiovascular Surgery, Kaw and colleagues ${ }^{3}$ from the Cardiovascular Meta-Analyses Research Group have performed a systematic review and meta-analysis of the searchable literature to identify the effect of diastolic dysfunction on mortality and major adverse cardiac events after cardiac surgery. Not only was the presence of dysfunction evaluated, the degree of dysfunction was found to be significantly adversely predictive as well.

The Cardiovascular Meta-Analyses Research Group ${ }^{3}$ used robust statistical methods that were critically reviewed, critiqued, and revised to allow us to bring the true effect of large studies across the world together to answer an important question. Diastolic dysfunction (and in particular severe diastolic dysfunction) has a less than favorable outcome in in terms of survival and major adverse cardiac events. Grade II dysfunction bordered on being predictive,

\section{References}

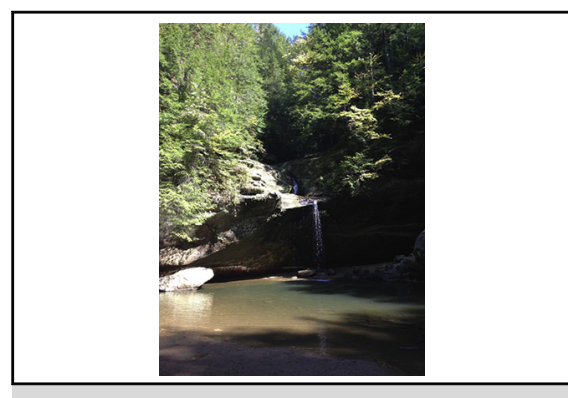

Forest among the trees (Hocking Hills State Park, Ohio).

\section{Central Message}

Diastolic dysfunction is an underappreciated risk factor in cardiac surgery. Although it is difficult to diagnose, it has important implications with respect to mortality and outcomes.

See Article page 1142 .

although the effect of grade III dysfunction, relative to normal function or either grade I or II dysfunction, proved to have the most severe effect. This effect on outcomes was seen regardless of echocardiographic approach used (transesophageal or transthoracic) and, perhaps more importantly, regardless of ejection fraction. ${ }^{3}$ These data would appear to support older data indicating that the majority of patients with dysfunction do not have remodeling or improved function after revascularization. ${ }^{4}$ We are seeing the importance of diastolic dysfunction evolve in patients who have heart failure with preserved ejection fraction, ${ }^{5,6}$ and thus the mere presence of a normal ejection fraction should not give us the comfort that it once did.

These data and the methods of their analysis truly take data from the patient and center level and allow it to be evaluated in aggregate and then reapplied to future patients. This methodology does have its limitations, although the power of pooling these studies and reaching a very convincing result in line with our evolving understanding of diastolic dysfunction is important. Although the study of Kaw and colleagues $^{3}$ does primarily consist of patients undergoing coronary artery bypass grafting and has yet to be fully disseminated and commented on, this research may become a truly potent contribution to the care of our patients.

1. Flachskampf FA, Biering-Sørensen T, Solomon SD, Duvernoy O, Bjerner T, Smiseth OA. Cardiac imaging to evaluate left ventricular diastolic function. JACC Cardiovasc Imaging. 2015;8:1071-93.

2. Opdahl A, Remme EW, Helle-Valle T, Lyseggen E, Vartdal T, Pettersen E, et al. Determinants of left ventricular early-diastolic lengthening velocity: independent 
contributions from left ventricular relaxation, restoring forces, and lengthening load. Circulation. 2009;119:2578-86.

3. Kaw R, Hernandez AV, Pasupuleti V, Deshpande A, Nagarajan V, Bueno H, et al. Effect of diastolic dysfunction on postoperative outcomes after cardiovascular surgery: a systematic review and meta-analysis. J Thorac Cardiovasc Surg. 2016;152: 1142-55.

4. Vaskelyte J, Stoskute N, Kinduris S, Ereminiene E. Coronary artery bypass grafting in patients with severe left ventricular dysfunction: predictive significance of left ventricular diastolic filling pattern. Eur $J$ Echocardiogr. 2001;2:62-7.

5. Ferrari R, Böhm M, Cleland JG, Paulus WJ, Pieske B, Rapezzi C, et al. Heart failure with preserved ejection fraction: uncertainties and dilemmas. Eur J Heart Fail. 2015; 17:665-71.

6. Huis In 't Veld AE, de Man FS, van Rossum AC, Handoko ML. How to diagnose heart failure with preserved ejection fraction: the value of invasive stress testing. Neth Heart J. 2016;24:244-51. 